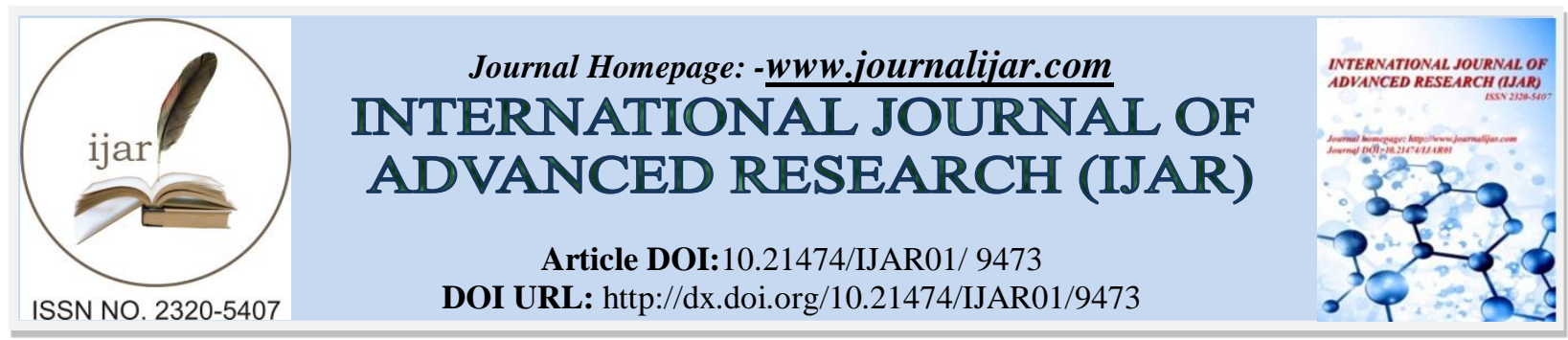

RESEARCH ARTICLE

\title{
INVESTIGATION OF LASER SPECKLE PATTERNS OF SOLAR CELLS.
}

H. El Ghandoor, G.M. Youssef, Mostafa A. El-Aasser and Alaa T. Ahmed.

Department of Physics, Faculty of Science, Ain Shams University, Cairo, Egypt.

\section{Manuscript Info}

Manuscript History

Received: 02 June 2019

Final Accepted: 04 July 2019

Published: August 2019

Key words:-

Speckle Photography technique, Speckle contrast, Roughness, Solar cell..

\begin{abstract}
Using an abrasive paper, the surface of commercial solar cells has been diffused with different micrometer features. Laser speckle patterns obtained from the different rough surface of solar cells were recorded using laser speckle photography technique. Different laser sources were used with a variable inclination with the solar cell optical axis. For each inclination angle, the contrast of the recorded speckle pattern was calculated. This speckle contrast gives a good indication about the solar cell roughness studied in this work. Furthermore, the speckle contrast changes significantly with the changing of the beam angle of incidence and its wavelength.
\end{abstract}

Copy Right, IJAR, 2019,. All rights reserved.

\section{Introduction:-}

Solar cells use a virtually infinite source of energy to generate electrical current directly from sun white light in a one-step conversion process. No other renewable energy source comes close to such an application [1]. The need for clean, renewable energy technologies to reduce the environmental effect of our increasing energy consumption is by now well established [2]. One way to attain higher efficiency of the solar cell is to increase the fraction of light that is absorbed by the solar cell, a strategy now commonly known as light trapping [3]. Typical elements used to achieve light trapping enhancement include introducing light scattering at rough surfaces and increasing the path length are presented [4]. It was found out that the interface morphology can play an important role in light trapping [5]. Therefore, it is important to investigate the degree of roughness of the solar cell surface [6]. Formation of speckle is due to the incidence of coherent light on a rough surface of height variations greater than the wavelength $\lambda$ of the light which is scattered in all directions [7]. These scattered wavelets interfere and form an interference pattern consisting of dark (distractive interference) and bright (constructive interference) spots named speckles which are randomly distributed in space [8]. Therefore, laser speckle is utilized for the analysis and study of the surface roughness of a solar wafer as well as for measuring the surface roughness of solar cells [9-11]. Also, the speckle pattern contrast gives a good implementation of the object surface roughness parameter [12-15]. The primary goal of this work is to study the relationship between the laser speckle contrast and the different time of 
mechanical roughness of the solar cell surface. Also, the behavior of the contrast at different angles of incidence and different wavelengths will be studied.

\section{Theory}

Surface texturing of the solar cell can enhance the light trapping by increasing the path length of the incident light as shown in Figure 1. This texturing can be realized mechanically or chemically [16-18]. Although the surface texturing increases the absorption of light, a part of the incident light will be scattered [19]. The intensity of the scattered wavelets carries important information about the surface texture. When illuminating the textured surface by coherent light such as laser, the scattered wavelets will interfere constructively and destructively to produce laser speckle patterns. The surface roughness can be extracted from the statistical properties "the contrast" of the speckle patterns [11]. The laser speckle contrast is based on the average intensity of the scattered light and it can be calculated from [10]

$$
C=\frac{I_{\max }-I_{\min }}{I_{\max }}
$$

where $I_{\max }$ is the average of the maximum intensity (bright spots) and $I_{\min }$ is the average of the minimum intensity (dark spots).

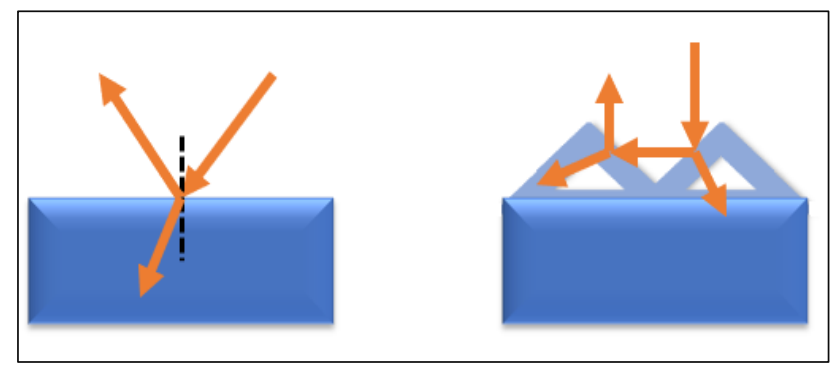

Figure 1:-An illustrative diagram about path length enhancements introducing light scattering at rough surfaces.

\section{Experiment}

A mechanical system has been made for diffusing the solar cell surface by an accurately adjusting micrometer to fix the specimen for the desired time. A commercial thin-film solar cell "Figure $2 \mathrm{a}$ " has been diffused mechanically using $0.01 \mu \mathrm{m}$ sandpaper disk for different operation times 15, 30, 50 seconds. The diffused surface of the solar cell is illuminated by a laser beam of light using the experimental set-up shown in Figure 2b. This set-up consists of a collimated laser beam. The beam is allowed to diverge through a condensing lens which expands the laser beam. A collimating imaging lens of $150 \mathrm{~mm}$ focal length and a diaphragm was used to form a collimated laser beam. This collimated beam has been allowed to fall on the solar cell as shown in Figure 2b, $\mathrm{c}$ at a different angle of incidence $\left(\theta=42^{0}, 50^{\circ}, 70^{\circ}, 78^{0}\right)$ measured between the incident laser rays and the normal to the solar cell surface. Four different laser sources, a He-Ne laser with $(632.8 \mathrm{~nm})$, a green laser diode $(536 \mathrm{~nm})$, a blue laser diode $(445 \mathrm{~nm})$ and red laser diode $(670 \mathrm{~nm})$ are used individually. In order to record the speckle patterns, a CCD camera were used. The recorded speckle images are manipulated with an Image Pro software program to extract the important information about the surface roughness. 

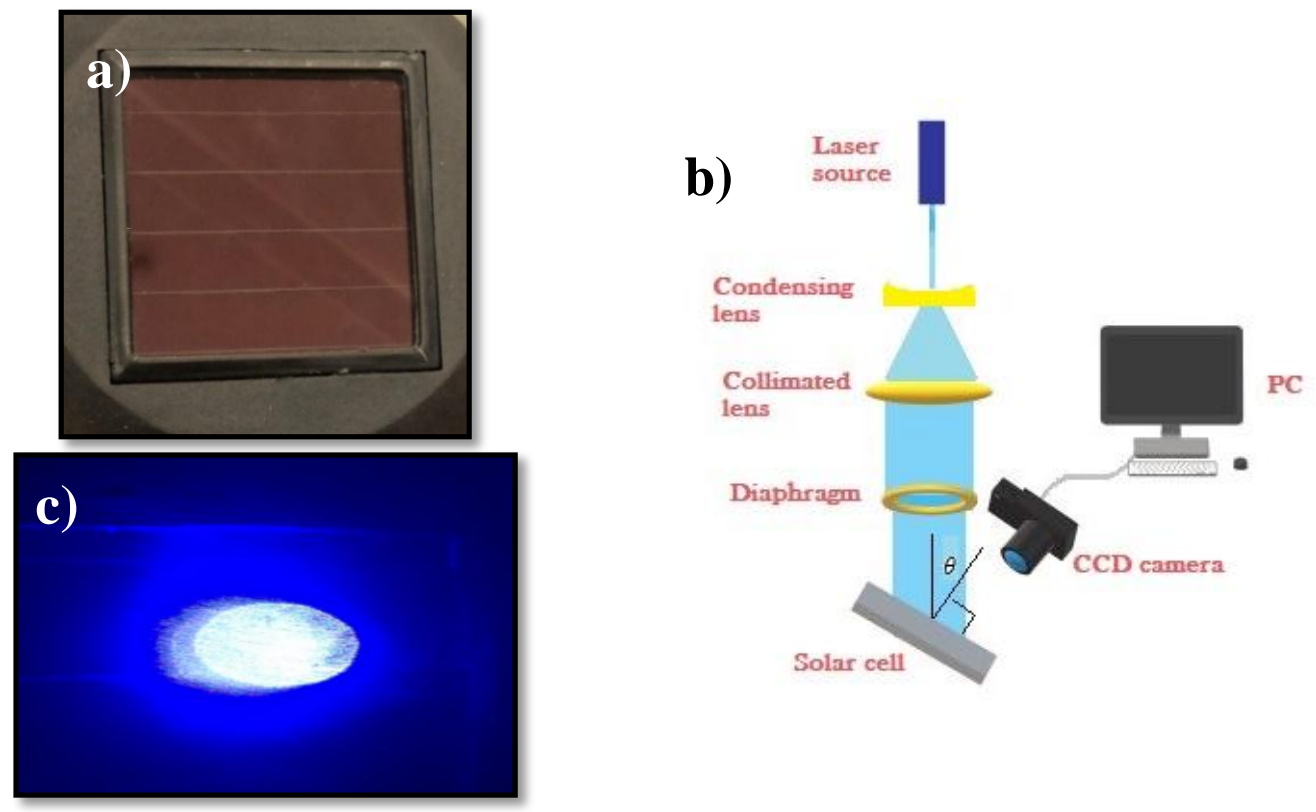

Figure 2:-(a) A commercial thin-film solar cell. (b) Laser speckle pattern recording system. (c) An Illustrative image of the roughened cell with the laser speckle pattern.

\section{Results:-}

Speckle patterns obtained using the three types of laser diode sources and the He-Ne laser source at different times of mechanical diffusing with $\theta=42^{0}$ is shown in table (1). Using Image pro software, the intensity fluctuations between dark and bright speckle spots obtained from falling the four different lasers on the different diffused solar cells with different diffusing times at $\theta=42^{0}$ is shown in Figure 3. It is obvious from Figure 3 that at this angle of incidence, the reference cell has the highest intensity fluctuations at all types of lasers used. This resulted because the reference cell has less roughness than the rest of the samples, which led to an increment in the intensity of the reflected waves.

Table 1:-The laser speckle patterns obtained using different laser sources at different times of mechanical roughening with $\theta=42^{0}$ :

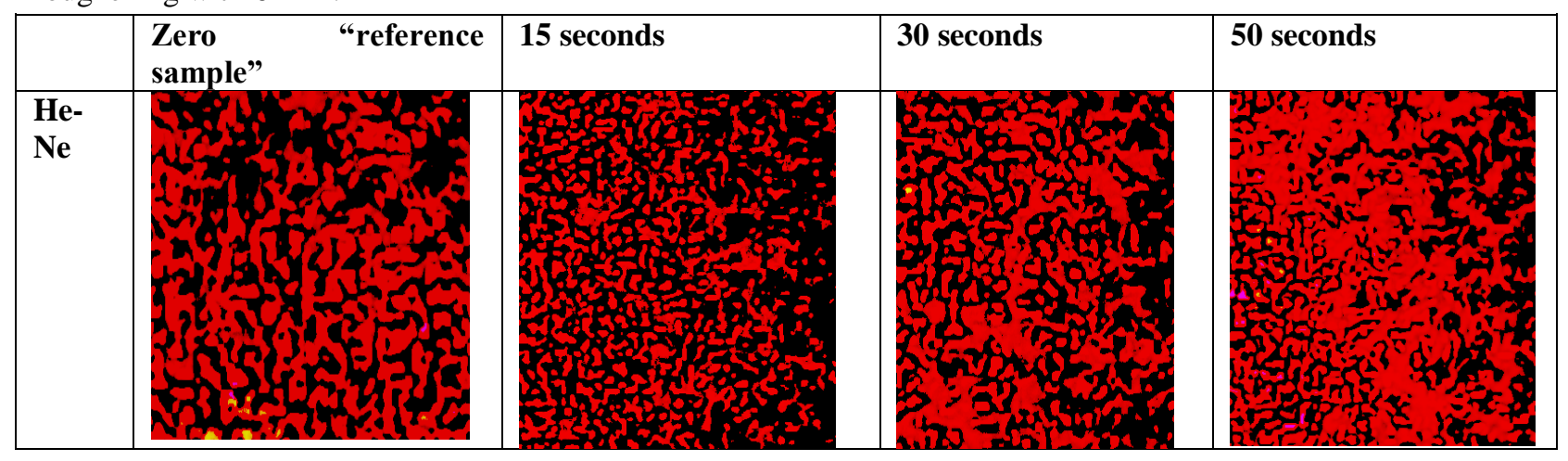




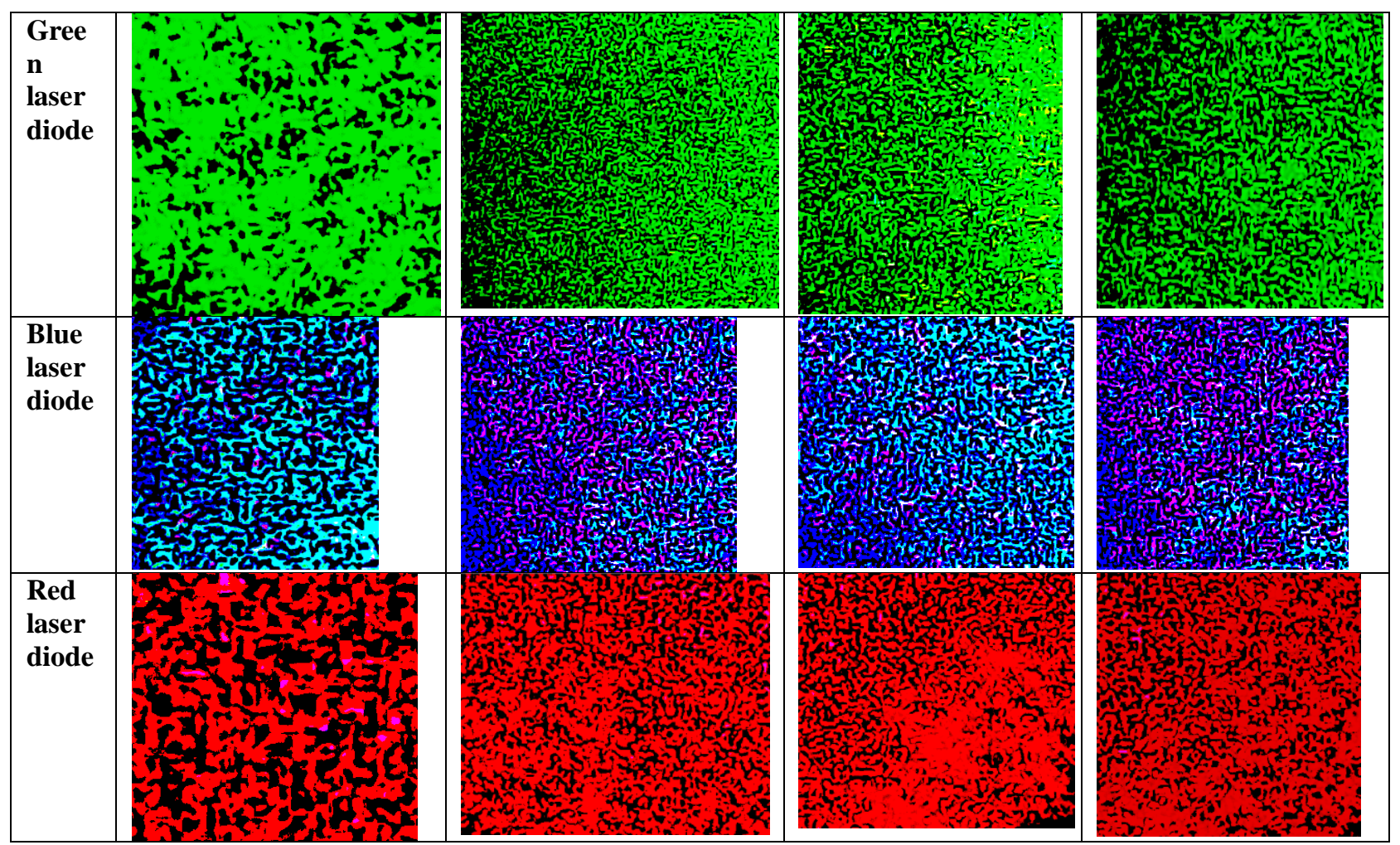

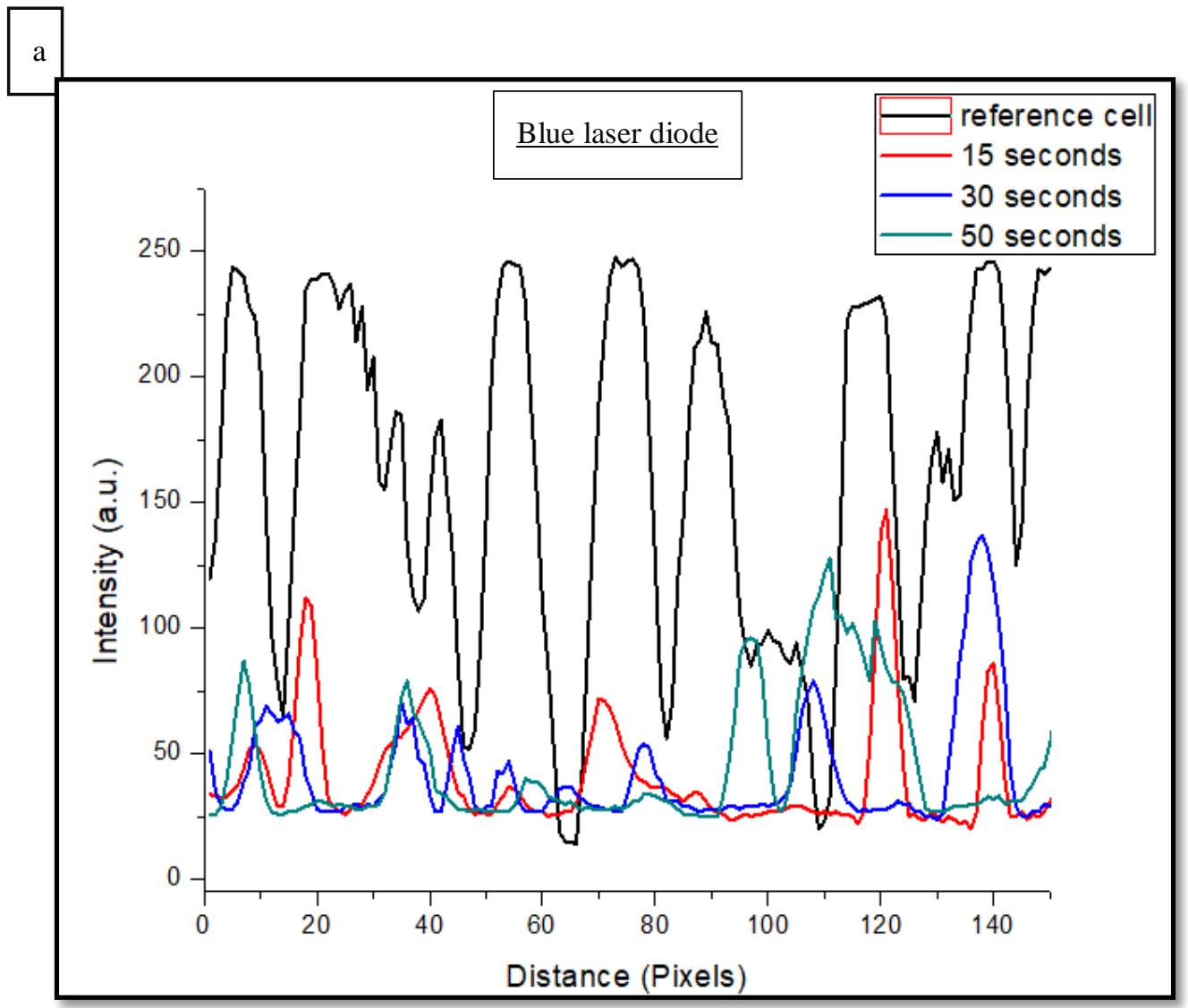



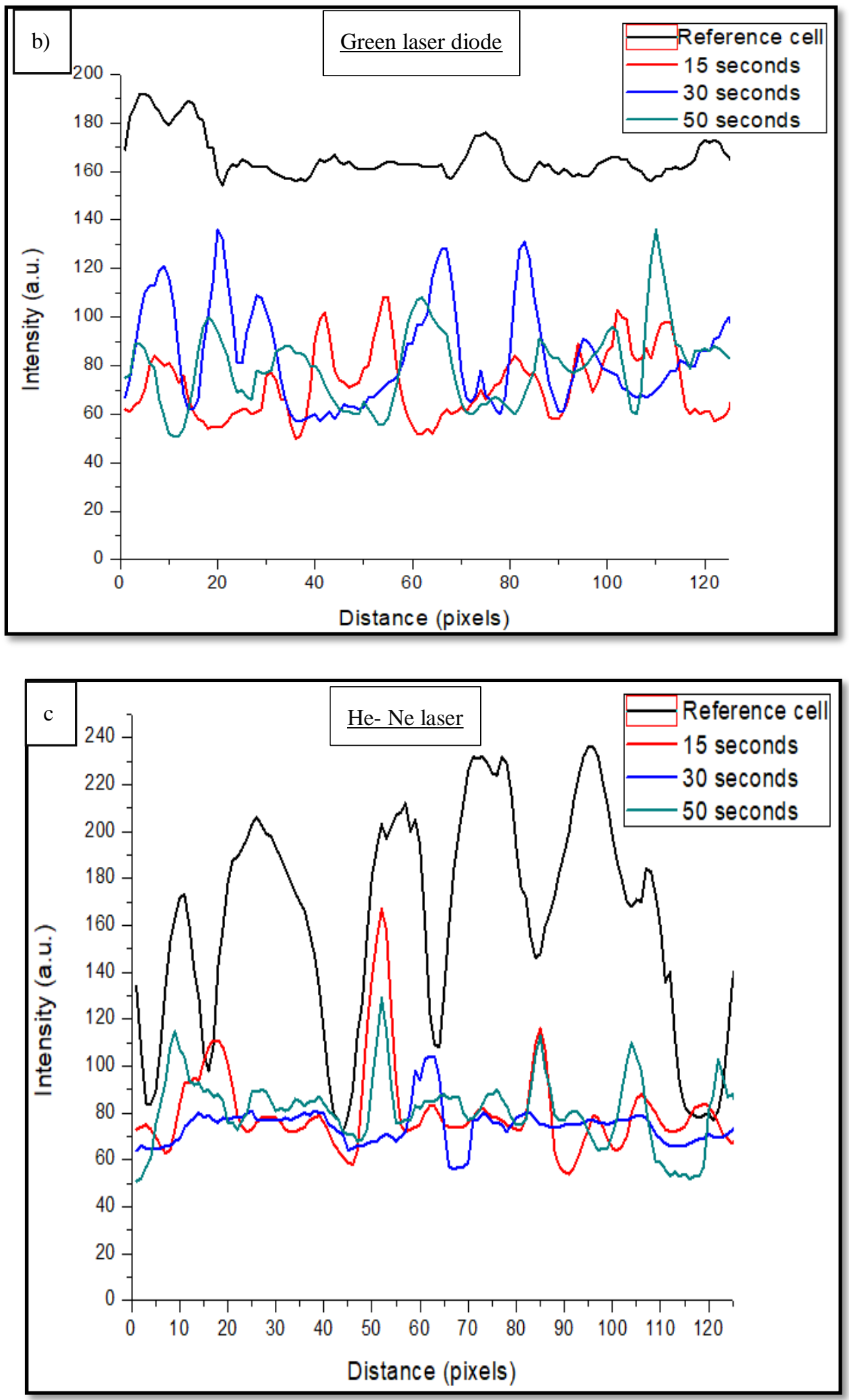


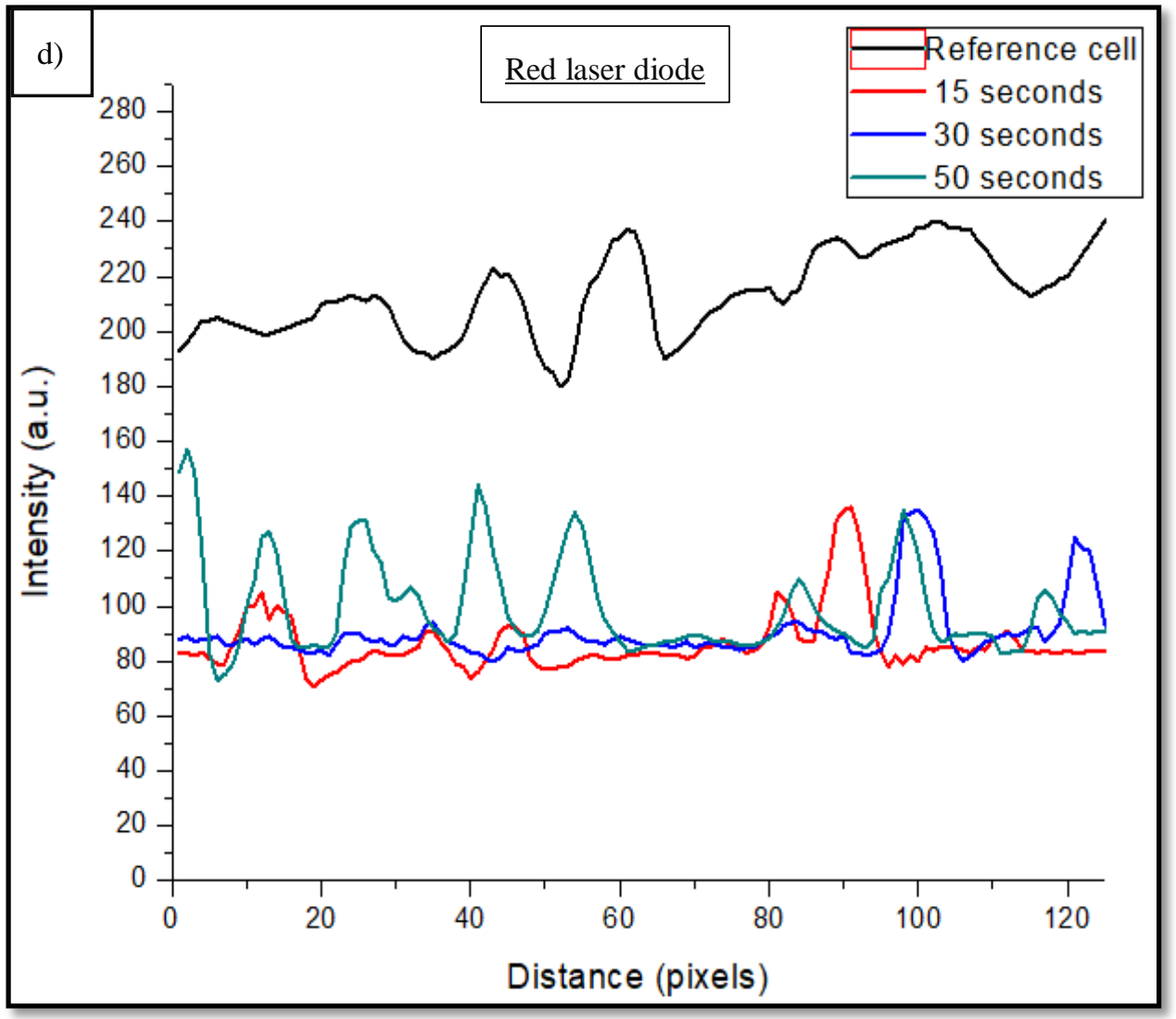

Figure 3:-The intensity fluctuations between bright and dark spots in the laser speckle patterns obtained from falling the laser beam on different roughnesses at $\theta=42^{0}$.

The contrast of the laser speckle was calculated using equation 1 . The relation between the contrast of the laser speckle patterns obtained using different types of lasers and the time of mechanical roughening is shown in Figure 4, where (a) at an angle of incidence $\theta=42^{\circ}$, (b) at $\theta=55^{\circ}$, (c) at $\theta=70^{\circ}$ and (d) at $\theta=78^{\circ}$. Also, the linear curve fitting for each wavelength is included. 

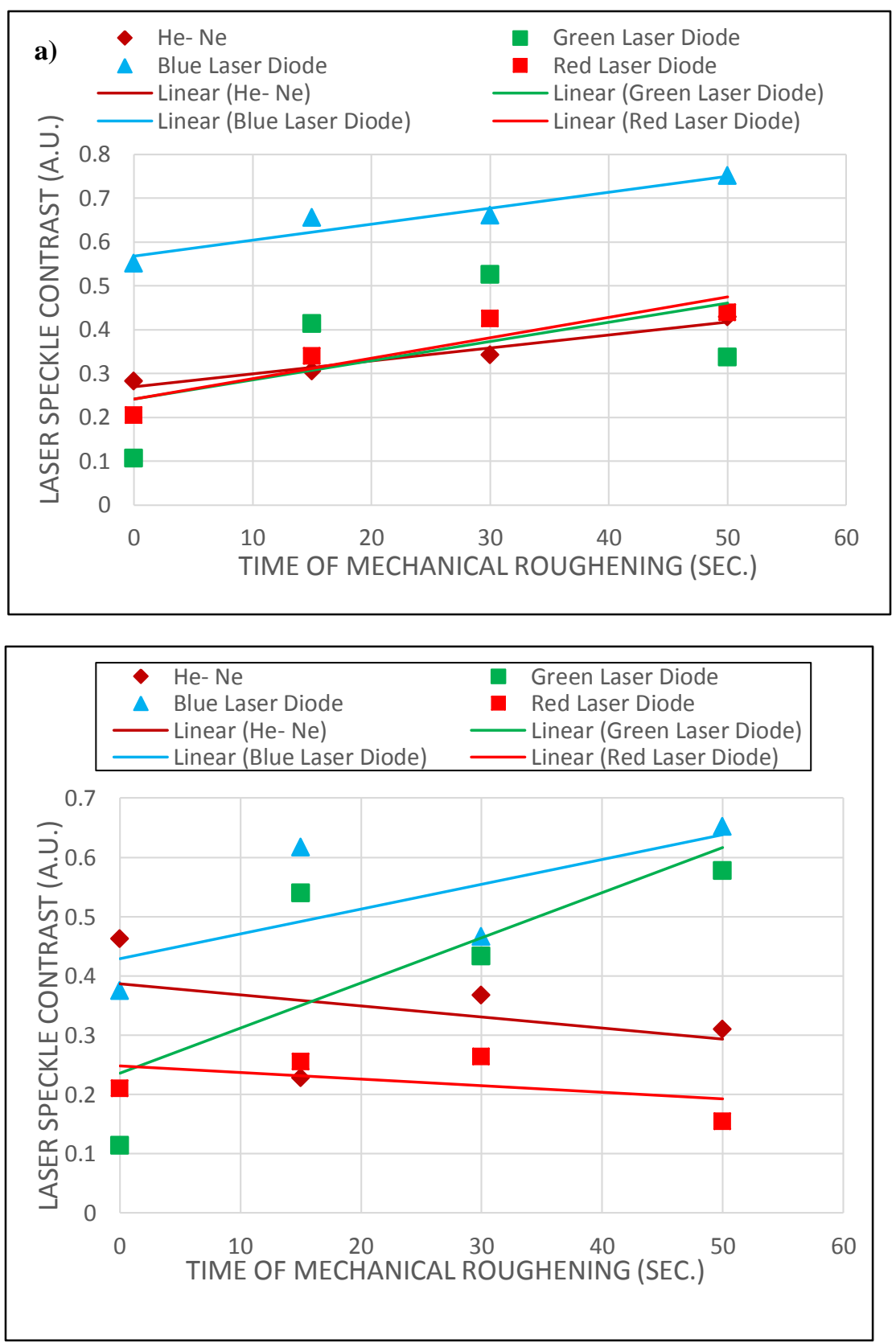

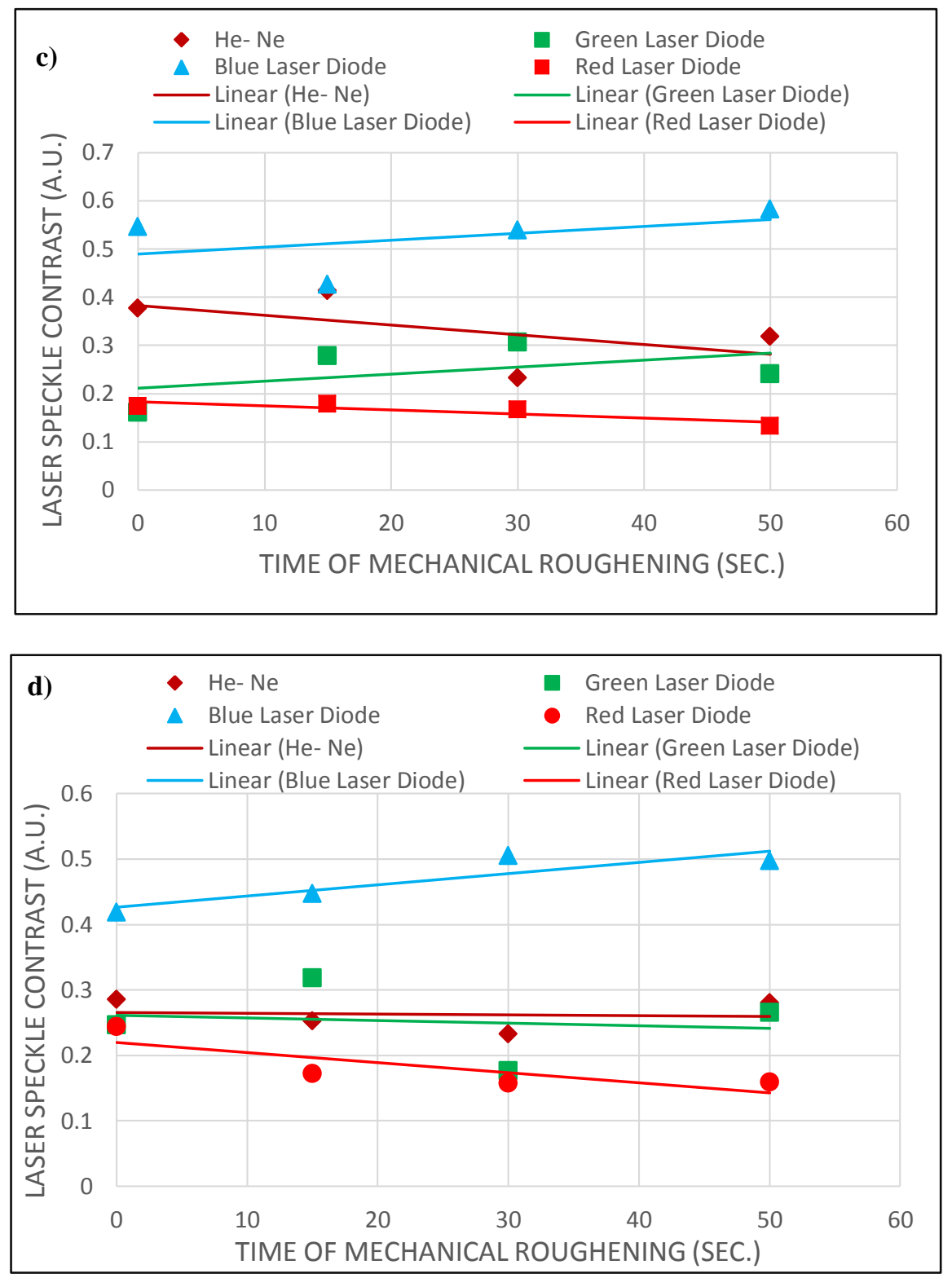

Figure 4:-The relation between the contrast of the laser speckle pattern obtained using four different types of lasers and the time of mechanical roughening. (a) $\theta=42^{0}$, (b) $\theta=55^{\circ}$, (c) $\theta=77^{\circ}$, (d) $\theta=78^{0}$.

\section{Discussion:-}

It is obvious from Figure 4 that the speckle contrast obtained using the blue laser diode increases with the increase of the time of roughening at all studied angles of incidence. This can be confirmed by Figure 3a whereas the speckle intensity distribution obtained using the blue laser diode has the highest $I_{\max }$ value and the lowest $I_{\min }$ value among the other laser sources used. This can give an impression of the blue laser beam " $445 \mathrm{~nm}$ " scattering from the investigated solar cell. Such that, this wavelength " $445 \mathrm{~nm}$ " is the most scattered wavelength even with increasing the mechanical roughening time and the angle of incidence.

The speckle contrast obtained using the green laser diode is also increased with the mechanical time of roughening at the all studied angles of incidence except for $\theta=78^{0}$. This means that the green laser beam " $536 \mathrm{~nm}$ " is strongly scattered by studied solar cell surface even after mechanical roughening. This is not the case when the green laser beam incident on the solar cell surface by $\theta=78^{\circ}$. The decrement in green speckle contrast with the mechanical 
roughening at $\theta=78^{\circ}$ may refer to the decreasing of that wavelength "536 nm" scattering and increasing its absorption by the solar cell surface.

The contrast obtained using the red laser diode "670 nm" and the He-Ne laser "632.8 nm" decreased with the time of roughening at all angles of incidence except for $\theta=42^{0}$ which has an increasing behavior with the time of the mechanical roughness. This may be resulted from increasing the solar cell absorption and decreasing scattering of the wavelengths $632.8,670 \mathrm{~nm}$ which is not the same case at $\theta=42^{0}$.

\section{Conclusion:-}

The surface of a commercial thin film solar cell has been roughened for different times mechanically. The laser speckle patterns have been obtained using four different laser sources (different wavelengths). The angle of incidence varied from 42 to 78 angles. The contrast of the laser speckle patterns was calculated. It is found that the speckle contrast obtained using the blue laser diode increases with the time of roughening at all studied angles of incidence. The green laser diode speckle contrast increased with the mechanical time of roughening at the all studied angles of incidence except for $\theta=78^{\circ}$. The He-Ne and the red laser diode speckles contrast decreased with the time of roughening at all angles of incidence except for $\theta=42^{0}$. This can give an indication about the scattering and the absorption of this kind of solar cells upon increasing the surface roughness. As a result, this study has succeeded in monitoring the relationship between the speckle contrast and the time of mechanical roughening. Also, the effect of changing the wavelength used and the angle of its incidence on the relationship between speckle contrast and time of mechanical roughening is illustrated successfully in this study.

\section{References:-}

1. Antonio Luque SSH (2003) Photovoltaic Science

2. Gielen D, Boshell F, Saygin D, et al (2019) The role of renewable energy in the global energy transformation. Energy Strateg Rev 24:38-50. https://doi.org/10.1016/j.esr.2019.01.006

3. Wang W, Qi L (2019) Light Management with Patterned Micro- and Nanostructure Arrays for Photocatalysis , Photovoltaics , and Optoelectronic and Optical Devices. Adv Funct Mater 1807275:1-29. https://doi.org/10.1002/adfm.201807275

4. CHELSEA CARLSON SH (2018) Disordered nanophotonic surfaces for enhanced light collection in

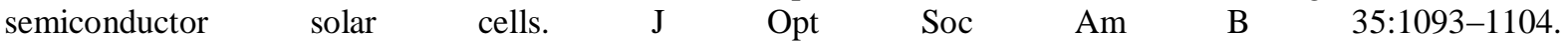
https://doi.org/https://doi.org/10.1364/JOSAB.35.001093

5. Seim E, Kohler A, Lukacs R, et al (2019) Chaos: a new mechanism for enhancing the optical generation rate in optically thin solar cells. In: Proc.SPIE

6. Velidandla V, Xu J, Hou Z, et al (2011) Texture process monitoring in solar cell manufacturing using optical metrology. Conf Rec IEEE Photovolt Spec Conf 001744-001747. https://doi.org/10.1109/PVSC.2011.6186291

7. Welford WT (2015) Laser Speckle and Applications in Optics. Phys. Bull. 31:205-205

8. Gåsvik KJ (2002) Optical metrology. 360

9. Lin CS, Haun CM, Hsien FS, et al (2011) Application of laser speckle technology in solar wafer roughness inspection system. Indian J. Pure Appl. Phys. 49:523-530

10. Hamed AM, El-Ghandoor H, El-Diasty F, Saudy M (2004) Analysis of speckle images to assess surface roughness. Opt. Laser Technol. 36:249-253

11. Goodman JW, Speckle L (1975) Related Phenomena', edited by JC Dainty

12. Persson U (1992) Real Time Measurement of Surface Roughness on Ground Surfaces Using Speckle-Contrast Technique Ulf Persson. Opt Lasers Eng 17:61-67. https://doi.org/https://doi.org/10.1016/0143-8166(92)90012$\mathrm{V}$

13. Dhanasekar B, Mohan NK, Bhaduri B, Ramamoorthy B (2008) Evaluation of surface roughness based on monochromatic speckle correlation using image processing. Precis Eng 32:196-206. https://doi.org/10.1016/j.precisioneng.2007.08.005

14. Postnov DD, Cheng X, Erdener SE, Boas DA (2019) Choosing a laser for laser speckle contrast imaging. Sci Rep 1-6. https://doi.org/10.1038/s41598-019-39137-x

15. Rey P (2017) ScienceDirect ScienceDirect ScienceDirect Speckle characterization of surface roughness obtained by laser models for optimization in Industry between used capacity and operational efficiency Speckle characterization of surface roughness obtained by laser. Procedia Manuf 13:519-525. https://doi.org/10.1016/j.promfg.2017.09.077 
16. Bender H, Szlufcik J, Nussbaumer H, et al (1993) Polycrystalline silicon solar cells with a mechanically formed texturization silicon solar cells with a mechanically formed texturization. Appl Phys Lett 62:21-24. https://doi.org/10.1063/1.109628

17. Park M, Kim HJ, Jeong I, et al (2015) Mechanically Recoverable and Highly Effi cient Perovskite Solar Cells : Investigation of Intrinsic Flexibility of Organic - Inorganic Perovskite. Adv Energy Mater 5:1-11. https://doi.org/10.1002/aenm.201501406

18. Rayerfrancis A, Bhargav PB, Ahmed N, et al (2018) Glass Surface Etching with Aluminium-Induced Texture Process for Thin Film Solar Cell Applications. Mater Lett 221:305-308. https://doi.org/10.1016/j.matlet.2018.03.154

19. Poprawe R, Boucke K, Hoffman D (2018) Interaction of Light and Matter. In: Tailored Light 1: High Power Lasers for Production. Springer Berlin Heidelberg, Berlin, Heidelberg, pp 179-204. 